\title{
Fatigue in the Danish general population. Influence of sociodemographic factors and disease
}

Torquil Watt, Mogens Groenvold, Jakob Bue Bjorner, Vibeke Noerholm, Niels-Anton Rasmussen, Per Bech

\begin{abstract}
Objective-To measure the levels of fatigue in the general population, and to examine how disease and sociodemographic factors influence fatigue. Design-Cross sectional questionnaire study in the Danish general population. Subjects-A random, age stratified sample of 1608 people aged 20-77 with an equal gender distribution (response rate $67 \%$ ). Main outcome measures-Five fatigue scales from the questionnaire Multidimensional Fatigue Inventory: General Fatigue, Physical Fatigue, Reduced Activity, Reduced Motivation and Mental Fatigue.

Results-Fatigue scores were skewed towards absence of fatigue. The General Fatigue and Physical Fatigue scales showed the highest fatigue levels while the Reduced Motivation scale showed lowest levels. Gender differences in fatigue scores were small, but the variability among women was higher-that is, more women had high scores. A multiple linear regression analysis showed that respondents of low social status and respondents with a depression had high fatigue scores on all scales, independent of other factors. Chronic somatic disease had an independent direct effect on Mental Fatigue, but for the rest of the scales, the effect of somatic disease depended on age, gender and/or whether the person was living alone. For example, General and Physical Fatigue decreased with age among healthy people, whereas scores on these scales increased with age among those with a somatic disease.

Conclusions-Physical and mental diseases play essential parts for the level of fatigue and as modulators of the associations between sociodemographic factors and fatigue. These interactions should be taken into account in future research on fatigue and sociodemographic factors and when data from clinical studies are compared with normative data from the general population.

(F Epidemiol Community Health 2000;54:827-833)
\end{abstract}

Disorde

Psychiatric Hospital in

Aarhus, Aarhus,

Denmark

N-A Rasmussen

Correspondence to: Dr Watt

(T.Watt@pubhealth.ku.dk)

Accepted for publication 3 April 2000 medical treatments. Fatigue has been shown to have a substantial impact on patients' self care activities $^{13}$ and, eventually, overall quality of life. ${ }^{14}{ }^{15}$ Finally, fatigue has been found to be a strong predictor of future morbidity ${ }^{16}$ and mortality. ${ }^{17}$

Despite its high prevalence and acknowledged importance, fatigue as a theoretical construct is insufficiently investigated. A number of papers have been dealing specifically with this topic, ${ }^{18-22}$ and some of the results of these studies are: fatigue in healthy people is usually temporary and is conceptualised as a consequence of physical or mental exertion. ${ }^{19}{ }^{20} \mathrm{In}$ patients suffering from a disease, only minimal physical or mental effort may result in fatigue, which may be prolonged, or fatigue may emerge without any preceding cause. ${ }^{18}{ }^{20}$ This may also be the case in otherwise healthy people, as in the burn out syndrome or certain cases of chronic fatigue syndrome. Scientifically, it is often viewed as a multidimensional, ${ }^{19}{ }^{21-23}$ continuous $^{19}$ construct, which should be rated by the people experiencing fatigue. ${ }^{18-20}$

The physiological basis of fatigue is also insufficiently understood. Several studies have tried to find physiological determinants of fatigue in diseased persons ${ }^{24-27}$; recently focus has been on associations between fatigue and a number of immunological parameters. ${ }^{28-34}$

The high prevalence in the general population has resulted in a growth of interest in the influence of clinical and sociodemographic factors on the experienced level of fatigue. Such research is important for the clarification of the aetiology of this symptom, for the development of a theoretical understanding of fatigue, and for the interpretation of the levels of fatigue found in patient populations.

The findings regarding the level and distribution of fatigue in the general population are contradictory. The prevalence rates range from $7 \%$ to $42 \%,{ }^{35}$ probably because there is no agreed upon definition of what comprises a fatigue case. ${ }^{18}$ Many studies have found higher prevalences or higher mean scores in women, ${ }^{13} 36-45$ whereas others found no such difference. ${ }^{5647}$ The results on the association between age and fatigue are even more contradictory. Some found no associations, ${ }^{563739444849}$ some found an increase of fatigue with age 30424345 while others found lower levels of fatigue in older people..$^{38450}$ Generally higher education and social status has been associated with less fatigue, ${ }^{3} 3740414851$ but some studies did not identify any such trend. ${ }^{15436}$ Strong associations with mental 
health have been reported, ${ }^{42}$ especially for depression, ${ }^{3}$ but also for anxiety, independent of depression. ${ }^{52}$

Some of these ambiguities may be caused by the way fatigue has been conceptualised. Until recently fatigue has been measured unidimensionally, often just dichotomously (that is fatigued versus non-fatigued). As mentioned above, a view of fatigue as a multidimensional, continuous construct, comprising physical, cognitive, affective and behavioural aspects has emerged. The various subdimensions of fatigue may have different relations with other factors. For example, general population studies of health status show that physical functioning is worse for older age groups, while mental health has the same level across age. ${ }^{53}$ Accordingly, it is probable that physical and mental fatigue have different relations with age. We therefore expect that some of the uncertainty regarding fatigue can be reduced by using multidimensional measures.

To measure the levels of the various aspects of fatigue in the general population we conducted a large survey in a random sample of the Danish general population, using the Multidimensional Fatigue Inventory (MFI-20)..$^{54}$ The development of this questionnaire was based on comprehensive patient interviews, literature studies and theoretical considerations. ${ }^{85}$ It assesses five dimensions of fatigue: General, Physical and Mental Fatigue, Reduced Activity and Reduced Motivation. General Fatigue refers to fatigue expressed by people in terms of statements like "I feel tired" and "I feel rested". Physical Fatigue refers to physical sensations related to the feelings of tiredness. ${ }^{56}$ Mental Fatigue refers to deficits in cognitive functioning, such as having difficulties concentrating. Finally, Reduced Activity covers not doing any useful activities and Reduced Motivation covers lack of motivation to initiate such activities. ${ }^{54}$ All of these dimensions were identified from in depth patient interviews.

Comparisons between fatigue and similar concepts from more well known questionnaires has not been done in head to head empirical studies. However, the content of the Vitality Scale of the SF-36 is closely related to General Fatigue; vital exhaustion, which has proved to be a measure with strong predictive power for identifying future cases of myocardial infarction, ${ }^{16}$ contains components from all of the five MFI-20 scales in one scale, together with a well represented depression component. Burn out is another related concept, but this concept has additional implications, like depersonalisation and devaluation, and relates to specific occupational settings. In these years, many instruments for measuring fatigue are emerging. ${ }^{10}{ }^{57-62}$

This paper reports the results of the use of the MFI-20 in a general population sample, and examines the relations between the five dimensions of fatigue and chronic disease, depression and sociodemographic factors.

\section{Methods}

SAMPLE

The study population was an age stratified sample of 1608 Danes drawn randomly from the Civil Registration System in Denmark that registers all Danes. The sample was designed to comprise 27 persons born in each year in the period 1918-1977. However, because of sampling procedures, the oldest four classes (aged 76-79) comprised a total of 96, not 108 persons as intended.

Data were collected by a postal questionnaire booklet, containing the MFI-20, the Major Depression Inventory ${ }^{63}$ (from which depression can be diagnosed according to the ICD-10) and additional questions (details below). Reminders were sent out twice.

\section{MFI-20}

The MFI-20 consists of 20 items. Each item is a statement, like "I feel tired", and the respondent has to indicate to what extent the statement is true, using a five level scale. As the instrument intends to measure fatigue as a state, sensitive to temporal changes from, for example, disease and treatment, the instruction refers to "the previous days". We do not have additional information about the duration of the fatigue. From the 20 items, five scales (each summarising four items) are generated: General Fatigue, Physical Fatigue, Mental Fatigue, Reduced Activity and Reduced Motivation (see Appendix). Each scale was constructed by summation of its four items, if at least half of the items were not missing. Missing items were substituted by the mean of the non-missing items. In this paper we have transformed the resulting scale scores linearly to a range of $0-100$, zero indicating absence of fatigue.

The MFI-20 was previously tested on 111 cancer patients receiving radiotherapy, 357 patients with "chronic fatigue syndrome", 481 psychology students, 158 medical students, 316 army recruits and 46 junior physicians. ${ }^{54} \mathrm{~A}$ confirmatory factor analysis confirmed that the questions actually described five different dimensions. Cronbach's $\alpha$ was high (mean 0.84). Comparisons between the different groups showed expected differences. Correlations between subscales and a general question about fatigue were $0.22-0.78$; confirming that the scales measure something different from the existing, one dimensional instruments. These validation results were reproduced in a comparative study of 141 Dutch and 134 Scottish cancer patients, where further support for the five dimensional fatigue concept was found. ${ }^{64}$

MFI-20 was independently translated from English to Danish by two skilled translators. Based on these translations a preliminary version was developed. This version was then translated back to English by two other, independent translators, one native American, the other native British and both fluent in Danish. All translators were instructed to aim at maximal equivalence, not necessarily literal translation. No problems were detected in the back translation, so the final Danish version has 
Table 1 Mean (SD) of the five fatigue scales in the total population and in sociodemographic groupings. The range of the scales are 0 to 100. Higher scores indicate more fatigue

\begin{tabular}{llllll}
\hline & $\begin{array}{l}\text { General } \\
\text { Fatigue }\end{array}$ & $\begin{array}{l}\text { Physical } \\
\text { Fatigue }\end{array}$ & $\begin{array}{l}\text { Reduced } \\
\text { Activity }\end{array}$ & $\begin{array}{l}\text { Reduced } \\
\text { Motivation }\end{array}$ & $\begin{array}{l}\text { Mental } \\
\text { Fatigue }\end{array}$ \\
\hline All (n=1082) & $35(28)$ & $33(27)$ & $26(27)$ & $18(19)$ & $24(24)$ \\
Women (n=544) & $37(30)$ & $34(28)$ & $25(27)$ & $16(19)$ & $23(25)$ \\
Men (n=533) & $33(26)$ & $32(26)$ & $27(26)$ & $20(19)$ & $24(23)$ \\
Age 20-29 (n=175) & $34(25)$ & $28(23)$ & $21(20)$ & $13(13)$ & $24(23)$ \\
Age 30-39 (n=207) & $33(23)$ & $28(22)$ & $18(20)$ & $15(15)$ & $22(22)$ \\
Age 40-49 (n=183) & $35(28)$ & $31(27)$ & $21(24)$ & $18(19)$ & $25(23)$ \\
Age 50-59 (n=185) & $37(28)$ & $34(27)$ & $27(25)$ & $18(18)$ & $25(24)$ \\
Age 60-69 (n=181) & $32(29)$ & $35(29)$ & $31(28)$ & $19(21)$ & $20(23)$ \\
Age 70-79 (n=151) & $39(34)$ & $44(34)$ & $42(35)$ & $25(24)$ & $26(29)$ \\
Social class I (n=134) & $32(25)$ & $31(24)$ & $22(24)$ & $16(17)$ & $19(21)$ \\
Social class II (n=208) & $29(24)$ & $28(25)$ & $19(21)$ & $14(16)$ & $19(20)$ \\
Social class III (n=232) & $36(29)$ & $34(28)$ & $26(27)$ & $19(19)$ & $24(24)$ \\
Social class VI (n=269) & $35(28)$ & $31(27)$ & $26(26)$ & $18(19)$ & $25(24)$ \\
Social class V (n=148) & $42(32)$ & $40(30)$ & $35(30)$ & $22(23)$ & $28(27)$ \\
$>3$ years education (n=246) & $32(25)$ & $31(25)$ & $22(24)$ & $16(19)$ & $20(22)$ \\
Apprenticeship (n=231) & $32(27)$ & $28(25)$ & $23(24)$ & $16(16)$ & $22(25)$ \\
$<3$ years education (n=292) & $35(28)$ & $32(27)$ & $25(25)$ & $17(18)$ & $24(22)$ \\
No education (n=199) & $43(31)$ & $43(31)$ & $38(32)$ & $25(23)$ & $28(28)$ \\
Cohabiting (n=778) & $34(27)$ & $32(26)$ & $24(25)$ & $17(18)$ & $22(23)$ \\
Living alone (n=296) & $37(29)$ & $35(29)$ & $31(29)$ & $19(21)$ & $27(26)$ \\
\hline
\end{tabular}

the same wording as the preliminary version ${ }^{65}$ (detailed report available on request).

SOCIODEMOGRAPHIC DATA

Respondents were asked about their year of birth, gender, marital status, whether they were living with a partner (cohabiting), their education, and occupation. Based on the data we determined the respondents' social class (I-V), ${ }^{66}$ group I being the most affluent. Data on chronic diseases were obtained using a checklist of chronic diseases, supplemented by an open question about any other disease.

\section{STATISTICAL ANALYSIS}

We conducted a multiple linear regression analysis with interaction terms to separate the effect of the different factors from each other. The sociodemographic variables included in the multivariate analysis were sex, age, education and cohabitation. Social class was omitted to avoid problems of colinearity with education. Cohabitation was chosen because many Danes live together in marriage-like relationships without being formally married. Somatic disease was analysed as a dichotomous variable (no compared with any somatic disease). Depression was also analysed dichotomously (no compared with minor, moderate or severe depression, according to ICD-10). All direct effects were kept in the model, but nonsignificant interaction terms were eliminated through a backwards selection method with exclusion criterion $p>0.05$. We also tested for non-linear relations between age and each scale (by age squared).

Student's $t$ test was used to compare pairs of means, and linear regression was used to test for trends. SAS PROC GLM was used for the regression analyses. ${ }^{67}$ As we consider this study as exploratory, we used a classic 5\% significance criterion without correction for multiple tests. If not otherwise specified, we only comment on the statistically significant results.
All analyses were performed separately for each sex, but results of this are reported only where gender differences were found.

\section{Results}

The response rate was $67 \%$, with 1082 validly answered questionnaires. The final sample had an equal representation of men and women $(50.5 \%$ women). As the original sample consisted of equal sized age strata, the age distribution is not, and is not expected to be, comparable to that of the whole population (see table 1). The response rate was slightly higher (73\%) among those aged 30-39, and lower (58\%) among respondents aged 70-79. Analyses stratified by age show that compared with the Danish population, people with low educational level are under represented, and those with intermediate level of education are over represented. ${ }^{68}$ Data completeness was high, with missing scale scores for only 0.00 (General Fatigue) to 0.18 per cent (Reduced Motivation and Mental Fatigue). Individual items were missing in 0.3 to 1.7 per cent. Unadjusted norm data for MFI-20 are shown in table 1. General Fatigue and Physical Fatigue had the highest mean scores ( 35 and 33 respectively), and Reduced Motivation the lowest (18). All scales had some positive skewness, attributable to a moderate floor effect (respondents with minimum score), between 14 and 27 per cent, in the total sample.

\section{SOCIODEMOGRAPHIC FACTORS}

Gender

Table 1 shows small numeric differences in mean scores between men and women. Women scored higher on General Fatigue $(p=0.023)$, and lower on Reduced Motivation ( $\mathrm{p}=0.0019)$. On General Fatigue, women had a greater standard deviation than men, and the percentage of women with maximum score (very tired) was 5.1 versus 1.7 for men (not shown in table).

Age

Scores for Physical Fatigue, Reduced Activity and Reduced Motivation increased with age $(\mathrm{p}<0.0001)$.

\section{Social status}

Respondents of lower social class reported more fatigue on all scales $(p<0.001)$. An exception was between group I and group II, where this trend was not evident in any scale. Shorter education was also associated with higher fatigue scores in all scales $(p<0.001)$.

\section{Cohabitation}

Cohabiting respondents scored lower on Reduced Activity and Mental Fatigue ( $p>0.0001$ and $\mathrm{p}=0.01$, respectively). Cohabiting men also scored lower on General Fatigue $(p=0.0224$, data not shown in table).

\section{CHRONIC DISEASE}

Table 2 shows that respondents who reported any somatic disease had higher means on all scales, particularly on General Fatigue, Physical Fatigue and Reduced Activity. Respondents 
Table 2 Mean (SD) of the five fatigue scales according to self reported chronic disease. Mean scores more than 25 points higher than for those without disease are shown in bold

\begin{tabular}{|c|c|c|c|c|c|}
\hline & $\begin{array}{l}\text { General } \\
\text { Fatigue }\end{array}$ & $\begin{array}{l}\text { Physical } \\
\text { Fatigue }\end{array}$ & $\begin{array}{l}\text { Reduced } \\
\text { Activity }\end{array}$ & $\begin{array}{l}\text { Reduced } \\
\text { Motivation }\end{array}$ & $\begin{array}{l}\text { Mental } \\
\text { Fatigue }\end{array}$ \\
\hline No somatic disease $(n=653)$ & $28(24)$ & $25(22)$ & $19(21)$ & $15(16)$ & $20(21)$ \\
\hline Somatic disease ${ }^{\star}(n=429)$ & $46(30)$ & $46(30)$ & $37(31)$ & $22(23)$ & $29(27)$ \\
\hline Asthma $(n=50)$ & $49(34)$ & $51(29)$ & $44(32)$ & $25(26)$ & $27(28)$ \\
\hline Back problems $(n=171)$ & $49(29)$ & $49(30)$ & $37(31)$ & $21(23)$ & $31(27)$ \\
\hline Bronchitis $(n=37)$ & $54(30)$ & $58(30)$ & $51(32)$ & $28(26)$ & $32(29)$ \\
\hline Cancer $(n=29)$ & $44(31)$ & $45(32)$ & $36(27)$ & $21(21)$ & $28(27)$ \\
\hline Diabetes $(n=20)$ & $41(28)$ & $48(29)$ & $43(35)$ & $22(24)$ & $28(23)$ \\
\hline Hypertension $(n=105)$ & $45(29)$ & $46(29)$ & $40(33)$ & $28(27)$ & $29(28)$ \\
\hline Ischaemic heart disease $(n=35)$ & $56(28)$ & $56(28)$ & $53(31)$ & $37(29)$ & $26(22)$ \\
\hline Migraine $(n=70)$ & $46(31)$ & $44(27)$ & $33(27)$ & $21(20)$ & $34(27)$ \\
\hline Rheumatic disease $(n=140)$ & $54(31)$ & $53(31)$ & $44(32)$ & $23(24)$ & $31(29)$ \\
\hline Stroke $(n=13)$ & $59(25)$ & $66(33)$ & $71(29)$ & $40(30)$ & $59(35)$ \\
\hline Other disease $(\mathrm{n}=186)$ & $47(31)$ & $45(30)$ & $40(33)$ & $23(24)$ & $29(29)$ \\
\hline Psychiatric disease $(n=49)$ & $59(30)$ & $58(28)$ & $50(31)$ & $31(24)$ & $44(30)$ \\
\hline Depression (ICD-10) $(\mathrm{n}=57)$ & $77(22)$ & $71(23)$ & $68(28)$ & $50(25)$ & $60(29)$ \\
\hline
\end{tabular}

The range of the scales are 0 to 100 and higher score indicates more fatigue. ${ }^{\star}$ All respondent with any of the somatic diseases, except "Other disease". +Self reported, including self reported depression. $\ddagger$ Based on the MDI-questionnaire assessing the criteria for depressive episode according to ICD-10. estimates the change in score associated with a 10 year increase in age. Interaction terms appear in situations where the effect of one variable is modified by another. An estimated score can be constructed for any group by simply adding the terms: for example, 40 year old women without education who has a depression had an estimated General Fatigue score of (Intercept $+2 \times \beta_{\text {Age }}+\beta_{\text {No education }}+\beta_{\text {Depression }}=$ ) $34.1+2 \times(-3.0)+5.3+38.5=71.9$. The score for the same group, but with somatic disease instead of depression would be (Intercept $+2 \times \beta_{\text {Age }}+\beta_{\text {No education }}+\beta_{\text {Somatic disease }}+2 \times \beta_{\text {Age } \times}$ Somatic disease $=) 34.1+2 \times(-3.0)+5.3+4.6+$ $2 \times 3.8=45.6$.

\section{Gender}

Men had higher scores for Reduced Activity. Among the somatically diseased, men also had higher Physical Fatigue and Reduced Motivation scores.

having had a stroke had exceptionally high mean scores. Respondents with ischaemic heart disease also had high means, except on Mental Fatigue. People with bronchitis and rheumatic disease had high scores for General Fatigue, Physical Fatigue and Reduced Activity.

Respondents with self reported psychiatric illness had very high scores on all scales, and those who according to ICD-10 criteria had a depression had even higher scores.

MULTIPLE REGRESSION ANALYSIS

In the multivariate analysis (table 3 ), the intercept (reference score) describes the mean score of a reference group: 20 year old women with more than three years of education, living with a partner and not having any depression or somatic illness. For all the descriptive categories listed in table 3, except age, the regression coefficient ( $\beta$ weight) estimates the change in score associated with belonging to the relevant category. For age the regression coefficient
Age

In the multivariate model, General and Mental Fatigue decreased linearly with age, while Reduced Motivation increased slightly. Reduced Activity had a non-linear relation: the mean score decreased until age 45 , but from this age it increased and from age 70 it became higher than at age 20 (fig 1). In the presence of somatic disease, General Fatigue, Physical Fatigue and Reduced Activity increased with age (fig 2). For Reduced Activity this was also the case for those with depression.

\section{Education}

Educated respondents had lower fatigue scores

\section{Cohabitation}

Respondents living with a partner had lower Reduced Activity scores, less effect of somatic disease on Physical Fatigue and less effect of depression on Reduced Motivation. on all scales except Mental Fatigue.

Table 3 Regression coefficients (with standard error of estimate in parentheses) from the multiple linear regression analysis. Coefficients with $p<0.05$ in bold. The reference score (=the intercept of the model) is the estimated score of a reference group comprising 20 year old women with more than three years of education, living with a partner and not having any depression or somatic illness. The regression coefficients estimates changes in mean score

\begin{tabular}{|c|c|c|c|c|c|}
\hline & General Fatigue & Physical Fatigue & $\begin{array}{l}\text { Reduced } \\
\text { Activity }\end{array}$ & $\begin{array}{l}\text { Reduced } \\
\text { Motivation }\end{array}$ & Mental Fatigue \\
\hline Reference score (intercept) & $34.1(2.5)$ & $27.5(2.5)$ & $16.9(3.0)$ & $9.1(1.6)$ & $18.6(2.0)$ \\
\hline Sex (being male) & $-2.3(1.6)$ & $-2.6(2.0)$ & $3.6(1.5)$ & $2.1(1.4)$ & $1.6(1.4)$ \\
\hline Age (per 10 years) & $-3.0(0.7)$ & $-0.80(0.7)$ & $-4.2(1.9)$ & $1.2(0.4)$ & $-1.5(0.5)$ \\
\hline Apprenticeship & $-1.0(2.3)$ & $-2.8(2.2)$ & $-0.2(2.1)$ & $-0.2(1.6)$ & $2.1(2.0)$ \\
\hline Short education & $0.9(2.1)$ & $-1.4(2.1)$ & $-0.1(2.0)$ & $0.8(1.5)$ & $2.4(1.9)$ \\
\hline No education & $5.3(2.5)$ & $6.4(2.4)$ & $7.8(2.3)$ & $6.3(1.7)$ & $4.1(2.2)$ \\
\hline Living alone & $1.4(1.9)$ & $-1.6(2.3)$ & $4.1(1.7)$ & $-0.1(1.3)$ & $1.9(1.6)$ \\
\hline Somatic disease & $4.6(3.9)$ & $-1.1(4.0)$ & $1.4(3.6)$ & $1.0(1.6)$ & $9.1(1.6)$ \\
\hline Depression & $38.5(3.5)$ & $33.1(3.4)$ & $24.3(7.4)$ & $26.6(3.1)$ & $47.3(5.3)$ \\
\hline \multicolumn{6}{|l|}{ Interactions: * } \\
\hline Age $\times$ Somatic disease & $3.8(1.1)$ & $3.9(1.1)$ & $3.5(1.0)$ & - & - \\
\hline Age $\times$ Depression & - & - & $4.2(1.9)$ & - & - \\
\hline Sex $\times$ Somatic disease & - & $7.8(3.1)$ & - & $4.4(2.2)$ & - \\
\hline Living alone $\times$ Somatic disease & - & $9.0(3.6)$ & - & - & - \\
\hline Living alone $\times$ Depression & - & - & - & $11.1(4.8)$ & - \\
\hline Somatic disease $\times$ Depression & - & - & - & - & $-17.0(6.5)$ \\
\hline $\mathrm{Age}^{2}$ & - & - & $0.85(0.3)$ & - & - \\
\hline$R^{2} \ddagger$ & 0.23 & 0.27 & 0.32 & 0.23 & 0.18 \\
\hline
\end{tabular}

The range of the scales are 0 to 100 and higher score indicates more fatigue. ${ }^{\star}$ Only statistically significant coefficients shown $(\mathrm{p}<0.05)$. $¥$ Raw $R^{2}$ estimating variance explained by the model. 


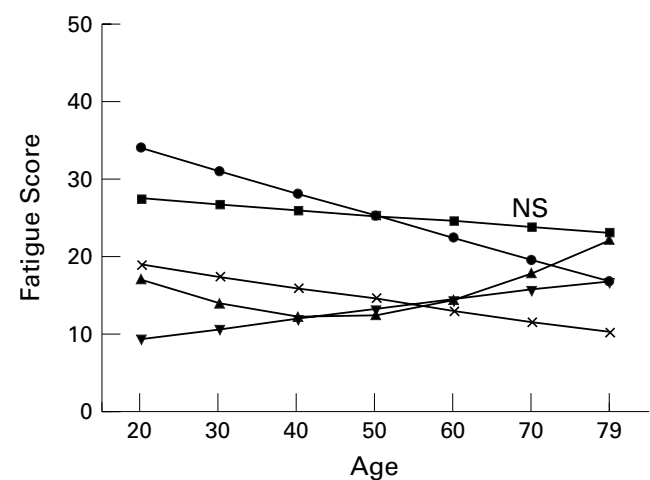

Figure 1 Association between expected fatigue scores and age among those without a chronic somatic disease. Scores are from the regression analysis-that is, controlled for gender, education, cohabitation and depression. The slope of Physical Fatigue regression line is not significantly different from zero (NS).

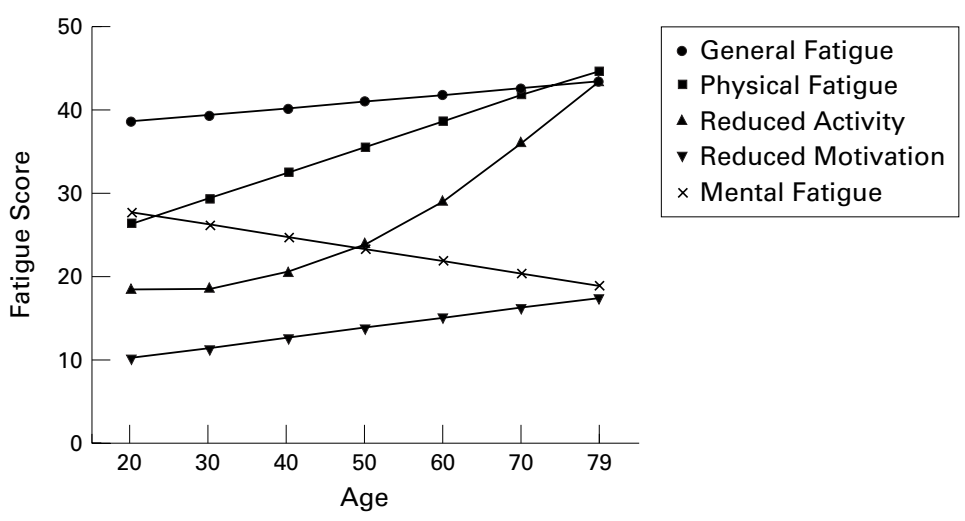

Figure 2 Association between expected fatigue scores and age among those with a chronic somatic disease. Scores are from the regression analysis-that is, controlled for gender, education, cohabitation and depression.

\section{Somatic disease}

Somatically diseased had higher scores for Mental Fatigue. On General Fatigue, Physical Fatigue and Reduced Activity the change in mean score associated with somatic disease differed with age: among the young there was no significant effect, whereas among the older, the somatically ill scored substantially higher on all three scales (compare fig 1 and 2).

\section{Depression}

Depressed respondents scored substantially higher on all scales, especially on Mental Fatigue. The negative somatic disease/ depression interaction parameter on Mental Fatigue indicates that somatic disease and depression did not exert additive effects on this scale.

Our models explain between 18 per cent (Mental Fatigue) and 32 per cent (Reduced Activity) of the variance in scale scores $\left(R^{2}\right)$.

In separate analyses for men and women the only substantial difference from the above was that men living alone had higher fatigue scores than women living alone.

\section{Discussion}

In this paper we report norm data for the MFI-20 in a large random sample from the Danish general population. These data can be used as a reference material for clinical investigations applying this instrument. A random, age stratified general population sample is bet-
KEY POINTS

- Fatigue in the general population was measured by five fatigue scales. These different aspects of fatigue had different relations with sociodemographic and clinical variables, indicating that a multidimensional concept of fatigue is indeed meaningful.

- Gender differences in mean fatigue scores were small, but the variability among women was higher - that is, more women had high fatigue scores.

- Respondents of low social status and respondents with a depression had high fatigue scores on all scales, independent of other factors.

- Multivariate analyses showed that physical and mental diseases play essential parts in determining the level of fatigue, and in modulating the impact of sociodemographic factors on fatigue.

- If the complex interactions between clinical and sociodemographic factors are ignored, analyses may show seemingly contradictory trends in fatigue.

ter suited for this purpose than the general practice populations used in previous research. ${ }^{40}{ }^{42}$ The large differences seen between groups differing with respect to sociodemographic and clinical factors suggest that to yield meaningful comparisons, "control groups" for interpretation should be selected with care. For example, differences in fatigue scores between disease and control groups could be biased by differences with regard to gender, age or educational level. Perhaps a new method for obtaining reference material for comparison would be to use the results from a multiple regression analysis with an interpretable intercept, like the one presented here. From such data the score of a precisely defined reference group could be obtained, without the potential loss of precision and power by reducing the sample size too much through a selection procedure.

The under representation of people with short education in the final sample might be attributable both to unreliability of self reported socioeconomic and educational status, or to selection bias. As we control for the effects of sociodemographic variables, the under representation of persons with low educational level should not have any major effect on the results reported here. Problems could occur, however, if the non-responders differ from the responders with respect to fatigue level. This could bias our general population mean and thus bias subsequent comparisons between our data and patient populations. Because of ethical considerations, we had no possibilities to evaluate the fatigue level of non-responders in this study.

The study shows that a multidimensional concept of fatigue may indeed be beneficial. There were large differences between scores on subscales and in their relations with other factors. For example, when examining the effect of 
different somatic diseases, respondents with a primarily physical disease, like bronchitis and ischaemic heart disease, had higher fatigue scores on the physically oriented scales General Fatigue, Physical Fatigue and Reduced Activity, while those with stroke and migraine also had high fatigue scores on the mentally oriented subscales Reduced Motivation and Mental Fatigue.

Our univariate analyses showed that on General Fatigue, women had only slightly higher mean score, but also, that women had greater variance in scores, and more women than men had very high scores. This may explain the previous contradictory findings, with on the one hand only small ${ }^{42-44} 47$ or no ${ }^{46} 48$ gender difference in mean scores, on the other quite large female/male odds ratios for being fatigued $^{35}{ }^{36}$ : on average, there is not much difference between men and women, but there is an excess of women among persons with very high levels of fatigue.

Our multivariate analyses underscore the importance of disease status in mediating and modifying the effect of sociodemographic variables on fatigue. Thus, among the nondiseased there was no difference between men and women on Physical Fatigue, whereas somatically diseased men were more fatigued than diseased women. Regarding age, we found a decrease with age on most scales among the non-diseased, compared with an increase with age in the diseased group. The same age tendency was seen on Reduced Activity with regard to depression. Our results on age may explain the ambiguity in earlier research. Fatigue may both increase and decrease with age, depending on whether or not the person has a chronic disease.

To the best of our knowledge, no previous studies have considered these modulating effects. It is possible that the interaction between disease and age reflects a change in disease spectrum with age-that is, that the chronic diseases encountered by older people cause more fatigue. We have not validated the self reported diseases, for example, against medical records. Depressed people may over report somatic disease and this may lead to an overestimation of the impact of somatic disease on fatigue. Future studies should investigate the age/disease interaction with fatigue for specific diagnostic groups, preferably based on physician rated diagnoses.

The only sociodemographic factor with a substantial influence of its own, regardless of disease status, was the socioeconomic factor, estimated by level of education. Uneducated reported more fatigue on all scales, except Mental Fatigue. This association between social status and fatigue has also been found in earlier studies. ${ }^{3} 371$

While the fatigue level of the somatically diseased was widely dependent on sociodemographic factors, the depressed respondents scored high on all scales, regardless of sociodemographic status. This is partly an inevitable finding ${ }^{15}$ as tiredness is one of the core symptoms in the depression diagnosis. Thus, fatigue and depression are clearly related constructs, but recently a prospective study showed differing time courses of fatigue and depression during radiotherapeutic treatment of cancer, thus indicating that fatigue and depression are not the same phenomenon. ${ }^{15}$ Our results also indicate this: depression only explained 14 per cent of the variance in General Fatigue (estimated by the standardised multiple regression coefficient).

We found a strong association between fatigue and morbidity and other researchers have found strong associations between fatigue and both morbidity and mortality in longitudinal studies. ${ }^{16}{ }^{17}$ Measures of fatigue may therefore be used to identify people susceptible to future morbidity who may be candidates for preventive initiatives.

The detailed information obtained with the continuous scales in this study speaks against the application of a cut point separating patients in fatigued versus non-fatigued in this kind of analyses. However, in a clinical setting, where decisions about whether to intervene or not are to be made, it might be useful with a cut point identifying cases. Continuous measurement should then be applied when monitoring possible effects of subsequent interventions.

An important clinical implication of this study is that self reported fatigue is not an inevitable and natural companion to aging - on the contrary, in fact. Therefore the physician should consider the presence of an unrecognised physical or mental disease when elderly patients complain of fatigue.

Funding: the project on Fatigue in the General Population has been supported by the Danish Medical Research Council, Danish University Antidepressant Group (DUAG), Janssen Cilag A/S, Denmark, The Wedell-Wedellsborg Foundation, Denmark, The Danielsen Foundation, Denmark.

Conflicts of interest: none.

\section{Appendix}

Overview of the items in each of the five scales of MFI-20

General Fatigue

I feel fit

I feel tired

I am rested

I tire easily

Physical Fatigue

Physically I feel only able to do a little

Physically I can take on a lot

Physically I feel I am in bad condition

Physically I feel I am in an excellent condition

Reduced Activity

I feel very active

I think I do a lot in a day

I think I do very little in a day

I get little done

Reduced Motivation

I feel like doing all sorts of nice things

I dread having to do things

I have a lot of plans

I don't feel like doing anything

Mental Fatigue

When I am doing something, I can keep my thoughts on it

I can concentrate well

It takes a lot of effort to concentrate on things

My thoughts easily wander

\footnotetext{
1 Norrelund N, Hollnagel H. Fatigue among 40-year-olds. [In Danish]. Ugeskr Laeger 1979;141:1425-9.

2 Ingham JG, Miller PM. Symptom prevalence and severity in a general practice population. F Epidemiol Community Health 1979;33:191-8.
} 
3 Fuhrer R, Wessely S. The epidemiology of fatigue and depression: a French primary- care study. Psychol Med

1995;25:895-905.
4 Bates DW, Schmitt W, Buchwald D, et al. Prevalence of fatigue and chronic fatigue syndrome in a primary care practice. Arch Intern Med 1993;153:2759-65.

5 Cathebras PJ, Robbins JM, Kirmayer LJ, et al. Fatigue in primary care: prevalence, psychiatric comorbidity, illness behavior, and outcome. If Gen Intern Med 1992;7:276-86.

6 Ridsdale L, Evans A, Jerrett W, et al. Patients who consult with tiredness: frequency of consultation, perceived causes of tiredness and its association with psychological distress. Br F Gen Pract 1994;44:413-16.

7 Ridsdale L. Tired all the time. BMf 1991;303:1490-1.

8 Smets EM, Garssen B, Schuster-Uitterhoeve AL, et al. Fatigue in cancer patients. Br f Cancer 1993;68:220-4

9 Richardson A, Ream E. The experience of fatigue and other symptoms in patients receiving chemotherapy. Eur $\mathcal{F}$ Cancer

10 Schwartz JE, Jandorf L, Krupp LB. The measurement of fatigue: a new instrument. F Psychosom Res 1993;37:75362.

11 Richardson A. Fatigue in cancer patients: a review of the literature. Eur f Cancer Care (Engl) 1995;4:20-32.

12 Appels A, Mulder P. Fatigue and heart disease. The association between "vital exhaustion" and past, present and future coronary heart disease. I Psychosom Res 1989;33: 727-38

13 Rhodes VA, Watson PM, Hanson BM. Patients' descriptions of the influence of tiredness and weakness on self-care abilities. Cancer Nurs 1988;11:186-94.

14 Hurny C, Bernhard J, Joss R, et al. "Fatigue and malaise" as a quality-of-life indicator in small-cell lung cancer patients. The Swiss Group for Clinical Cancer Research (SAKK). Support Care Cancer 1993;1:316-20.

15 Visser MR, Smets EM. Fatigue, depression and quality of life in cancer patients: how are they related? Support Care life in cancer patients:

16 Appels A, Mulder P. Excess fatigue as a precursor of myocardial infarction. Eur Heart 7 1988;9:758-64.

17 Avlund K, Schultz-Larsen K, Davidsen M. Tiredness in daily activities at age 70 as a predictor of mortality during the next 10 years. F Clin Epidemiol 1998;51:323-33.

18 Berrios GE. Feelings of fatigue and psychopathology: a conceptual history. Compr Psychiatry 1990;31:140-51.

19 Glaus A, Crow R, Hammond S. A qualitative study to explore the concept of fatigue/tiredness in cancer patients and in healthy individuals. Eur f Cancer Care (Engl) 1996 5:8-23.

20 Ream E, Richardson A. Fatigue: a concept analysis. Int $\mathcal{F}$ Nurs Stud 1996;33:519-29.

21 Tiesinga LJ, Dassen TW, Halfens RJ. Fatigue: a summary of the definitions, dimensions, and indicators. Nurs Diagn 1996;7:51-62.

22 Dalakas MC, Mock V, Hawkins MJ. Fatigue: definitions, mechanisms, and paradigms for study. Semin Oncol 1998;25:48-53.

23 Salmon P, Hall GM. A theory of postoperative fatigue: an interaction of biological, psychological, and social processes. Pharmacol Biochem Behav 1997;56:623-8.

24 Baschetti R. Cortisol deficiency may account for elevated apoptotic cell population in patients with chronic fatigue syndrome. F Intern Med 1999;245:409-10.

25 Breukink SO, Strijbos JH, Koorn M, et al. Relationship between subjective fatigue and physiological variables in patients with chronic obstructive pulmonary disease. Respir Med 1998; 92:676-82.

26 Cowley AJ. Are breathlessness and fatigue in chronic heart failure due to the same pathophysiological abnormality? Eur Heart f 1995;16:1-2.

27 Demitrack MA. Neuroendocrine aspects of chronic fatigue syndrome: a commentary. Am f Med 1998;105:11-14S.

28 Bennett BK, Hickie IB, Vollmer-Conna US, et al. The relationship between fatigue, psychological and immunological variables in acute infectious illness. Aust N Z F Psychiatry variables in acute

29 Drent M, Wirnsberger RM, de Vries J, et al. Association of fatigue with an acute phase response in sarcoidosis. Eur fatigue with an acute ph
Respir f 1999;13:718-22.

30 Glaser R, Kiecolt-Glaser JK. Stress-associated immune modulation: relevance to viral infections and chronic fatigue syndrome. Am f Med 1998;105:35-42S

31 Greenberg DB, Gray JL, Mannix CM, et al. Treatmentrelated fatigue and serum interleukin-1 levels in patient during external beam irradiation for prostate cancer. $\mathcal{F}$ Pain Symptom Manage 1993;8:196-200

32 Jayson GC, Middleton M, Lee SM, et al. A randomized phase II trial of interleukin 2 and interleukin 2- interferon alpha in advanced renal cancer. Br f Cancer 1998;78:3669.

33 Natelson BH, LaManca JJ, Denny TN, et al. Immunologic parameters in chronic fatigue syndrome, major depression, and multiple sclerosis. Am f Med 1998;105:43-49S.

34 Whiteside TL, Friberg D. Natural killer cells and natural killer cell activity in chronic fatigue syndrome. Am $\mathcal{F}$ Med killer cell activity

35 Lewis G, Wessely S. The epidemiology of fatigue: more questions than answers. If Epidemiol Community Health 1992;46:92-7.
36 Chen MK. The epidemiology of self-perceived fatigue among adults. Prev Med 1986;15:74-81

37 Hickie IB, Hooker AW, Hadzi-Pavlovic D, et al. Fatigue in selected primary care settings: sociodemographic and psychiatric correlates. Med f A ust 1996;164:585-8.

38 Tibblin G, Bengtsson C, Furunes B, et al. Symptoms by age and sex. The population studies of men and women in
Gothenburg, Sweden. Scand $\mathcal{F}$ Prim Health Care 1990;8:917.

39 Nisenbaum R, Reyes M, Mawle AC, et al. Factor analysis of unexplained severe fatigue and interrelated symptoms: overlap with criteria for chronic fatigue syndrome. $A m \mathcal{F}$ Epidemiol 1998;148:72-7.

40 van Mens-Verhulst J, Bensing J. Distinguishing between chronic and nonchronic fatigue, the role of gender and age. Soc Sci Med 1998;47:621-34.

41 Wessely S, Chalder T, Hirsch S, et al. The prevalence and morbidity of chronic fatigue and chronic fatigue syndrome: a prospective primary care study. Am f Public Health 1997; 87: $1449-55$.

42 Pawlikowska T, Chalder T, Hirsch SR, et al. Population based study of fatigue and psychological distress. BMF 1994;308:763-6.

43 Lawrie SM, Manders DN, Geddes JR, et al. A populationbased incidence study of chronic fatigue. Psychol Med 1997;27:343-53.

44 Lichstein KL, Means MK, Noe SL, et al. Fatigue and sleep disorders. Behav Res Ther 1997;35:733-40.

45 Appels A. Inflammation and the mental state before an acute coronary event. Ann Med 1999;31 (suppl 1):41-4.

46 Wessely S, Chalder T, Hirsch S, et al. Postinfectious fatigue: prospective cohort study in primary care. Lancet 1995;345: 1333-8.

47 Hardy GE, Shapiro DA, Borrill CS. Fatigue in the workforce of National Health Service Trusts: levels of symptomatology and links with minor psychiatric disorder, demographic, occupational and work role factors. $\mathcal{F}$ Psychosom Res 1997;43:83-92.

48 David A, Pelosi A, McDonald E, et al. Tired, weak, or in need of rest: fatigue among general practice attenders. $B M \mathcal{F}$ 1990:301:1199-202.

49 Ridsdale L, Evans A, Jerrett W, et al. Patients with fatigue in general practice: a prospective study. BMF 1993;307:103-

50 Hublin C, Kaprio J, Partinen M, et al. Daytime sleepiness in an adult, Finnish population. F Intern Med 1996;239:41723

51 van Mens-Verhulst J, Bensing JM. Sex differences in persistent fatigue. Women Health 1997;26:51-70.

52 Montgomery GK. Uncommon tiredness among college undergraduates. F Consult Clin Psychol 1983;51:517-25.

53 McHorney CA, Kosinski M, Ware JEJ. Comparisons of the costs and quality of norms for the SF-36 health survey collected by mail versus telephone interview: results from a national survey. Med Care 1994;32:551-67.

54 Smets EM, Garssen B, Bonke B, et al. The Multidimensional Fatigue Inventory (MFI) psychometric qualities of an instrument to assess fatigue. $\mathcal{F}$ Psychosom Res 1995;39: $315-25$

55 Smets EM A. Fatigue in cancer patients undergoing radiotherapy. [Thesis]. Amsterdam: University of Amsterdam, 1997.

56 Smets EM, Visser MR, Willems-Groot AF, et al. Fatigue and radiotherapy: (A) experience in patients undergoing treatment. Br f Cancer 1998;78:899-906.

57 Chalder T, Berelowitz G, Pawlikowska T, et al. Development of a fatigue scale. $\mathcal{F}$ Psychosom Res 1993;37:147-53.

58 Stein KD, Martin SC, Hann DM, et al. A multidimensional measure of fatigue for use with cancer patients. Cancer Pract 1998;6:143-52.

59 Mendoza TR, Wang XS, Cleeland CS, et al. The rapid assessment of fatigue severity in cancer patients: use of the Brief Fatigue Inventory. Cancer 1999;85:1186-96.

60 Krupp LB, LaRocca NG, Muir-Nash J, et al. The fatigue severity scale. Application to patients with multiple sclerosis and systemic lupus erythematosus. Arch Neurol 1989;46: $1121-3$.

61 Schwartz AL. The Schwartz Cancer Fatigue Scale: testing reliability and validity. Oncol Nurs Forum 1998;25:711-17. 62 Hann DM, Jacobsen PB, Azzarello LM, et al. Measurement of fatigue in cancer patients: development and validation of the Fatigue Symptom Inventory. Qual Life Res 1998;7:30110

63 Bech P, Wermuth L. Applicability and validity of the Major Depression Inventory in patients with Parkinson's disease. Nord f Psychiatry 1998;52:305-9.

64 Smets EM, Garssen B, Cull A, et al. Application of the multidimensional fatigue inventory (MFI-20) in cancer patients receiving radiotherapy. Br f Cancer 1996;73:241-5.

65 Groenvold M. Report on the translation of the Multidimensional Fatigue Inventory (MFI20) from English to Danish. Copenhagen: 1997.

66 Hansen EJ. Inequality in the welfare state. In: Erikson R, Hansen EJ, Ringen S, et al, eds. The Scandinavian model. New York: M E Sharpe, 1987.

67 SAS Institute. SAS/STAT user's guide. Cary: SAS Institue Inc, 1990.

68 Statistics Denmark. Statistical yearbook 1998. Copenhagen: Statistics Denmark, 1998. 